\title{
Morphoanatomical Symptomatology and Osmotic Behavior of Grape Berry Shrivel
}

\author{
Bhaskar Bondada ${ }^{1}$ \\ Washington State University Tri-Cities, Department of Horticulture and Landscape Architecture, \\ 2710 University Drive, Richland, WA 99354 \\ Markus Keller \\ Irrigated Agricultural Research and Extension Center, Washington State University, 24106 N. Bunn \\ Road, Prosser, WA 99350
}

\begin{abstract}
Additional INDEX wORDs. cell viability, CFDA, crystals, mesocarp, microscopy, osmotic potential, Vitis vinifera
Abstract. Berry shrivel, a physiological disorder, adversely affects ripening of grape (Vitis vinifera L.) berries; however, its causes are unknown. We adopted a holistic approach to elucidate symptomatology, morphoanatomy, and osmotic behavior of grape berry shrivel. Berries from healthy and afflicted vines were analyzed compositionally and with various techniques of microscopy. Healthy berries developed all physical and compositional attributes desirable for wine-making. Conversely, berry shrivel berries were grossly metamorphosed manifested as shriveling of the pericarp, which paralleled with loss of membrane competence in the mesocarp cells causing its collapse and a loss of brush. The most intriguing observation was the presence of non-druse crystals. These berries had high osmotic potential $\left(\psi_{\mathrm{S}}\right)$ as a result of low accumulations of sugar and potassium. Nonetheless, the seed morphology, structure, and viability were similar to healthy seeds. Berry shrivel grotesquely modified grape berries both compositionally and structurally, which was paralleled by their inability to accumulate sugars followed by cell death in the mesocarp. Although the mechanisms of berry shrivel remain uncertain, our study provides valuable background information for generating suitable guidelines to minimize the incidences of berry shrivel and also to design future studies toward unraveling the mechanistic basis of berry shrivel.
\end{abstract}

The composition of fully ripened grape berries at harvest constitutes the basis for key ingredients essential for making an infinite variety of value-added products such as wine and spirits. Because berries represent an integrated, systematic structure of tissues consolidated almost in a spherical symmetry, these ingredients are tastefully stratified in three different tissue strata encompassing the outer exocarp (skin), the median mesocarp, and the inner endocarp. Collectively these strata comprise the pericarp in whose locules reside in two to four seeds, two in each locule. Of these three tissues, the translucent and hydrated mesocarp composes the greater portion $(85 \%$ to $87 \%)$ of the berry's spherical volume (Coombe, 1992; Hardie et al., 1996). This hydrostatically pressurized mesocarp, the thickest of all strata, keeps the green- to purple- to black-colored exocarp enriched with anthocyanins in red cultivars taut with its epicuticular wax platelets evenly spread as powdery bloom throughout the stretched surface (Hardie et al., 1996). Concurrently, the turgid vacuoles of parenchymatous mesocarp cells serve as the main reservoir of juice or cell sap whose largest components include water, sugar in the form of glucose and fructose, and organic acids (mostly malate and tartarate); altogether these make up $99.5 \%$ of the juice mass and hence are the major determinants of berry size and fruit quality (Coombe, 1992;

Received for publication 7 Nov. 2011. Accepted for publication 14 Nov. 2011. Financial support was provided by the Washington State Grape and Wine Research Program.

We thank Drs. Michael Knoblauck, Valerie Lynch-Holm, and Christine Davitt of the Washington State University Franceschi Microscopy Imaging Center and Mr. Bruce Arey of the EMSL microscopy facility for their technical assistance. We also thank Dr. Bill Riley and Jason Schlegel of Ste. Michelle Wine Estates and Tedd Wildman of Stone Tree Vineyard for allowing us to collect grape samples in their vineyards.

${ }^{1}$ Corresponding author. E-mail: bbondada@wsu.edu.
Keller, 2010; Tilbrook and Tyerman, 2006). Phenolics along with terpenoids, lipids, cellulose, and pectin make up the remaining $0.5 \%$ of the components of the berry (Tilbrook and Tyerman, 2006). Compositionally, sugars are the key ingredients because their accumulation in vacuoles typifies ripening and hence is a major commercial consideration for grape growers, wine-makers, and processors. In particular for wine, sugars determine alcohol level and shape the flavor profile by controlling the production of quality-related secondary compounds (Coombe, 1992). Furthermore, sugars contribute to the berry's expansive growth; i.e., an increase in volume by providing the osmotic driving force for water entry into growing cells as well as modulating gene expression through signaling mechanisms (Koch, 1996; Matthews and Shackel, 2005). In view of their multifaceted contributions, sugars are often used as an indicator of maturity and are sometimes used as a basis for pricing of grapes.

Viticulturists use the French word véraison to describe the initiation of berry ripening, which represents one of the modules of berry's double sigmoidal growth curve wherein an initial intense mitotic activity causing a rapid increase in size is followed by a lag period with no increase in volume. During ripening, sucrose is transported from leaves to berries through a tightly regulated process that is well coordinated with growth and development (Coombe, 1992; Keller, 2010). Once in the berries, sucrose is enzymatically cleaved and massively accumulated in approximately equimolar amounts as glucose and fructose, particularly in wine grape cultivars (Coombe, 1992; Kliewer, 1967; Matthews and Shackel, 2005). Concomitant with sugar accumulation, berry volume and softness increase, whereas malic acid declines, and in red grape cultivars, the skin changes color as a result of the accumulation of anthocyanins (Keller, 2010; Matthews and Shackel, 2005). Because ripening is a highly coordinated, genetically programmed irreversible phenomenon, 
there is an increased risk of developing ripening disorders with undesirable quality attributes when fruit start ripening (Brady, 1987). For instance, tomato (Solanum lycopersicum L.) fruit develops numerous ripening disorders (e.g., Guichard et al., 2001). Stone fruit disorders such as split and shattered pits and double fruit of peach [Prunus persica L. (Ceponis et al., 1987)] and albino and malformed fruit of strawberry [Fragaria $\times$ ananassa (L.) Duch. (Singh et al., 2007)], all of which reduces fresh market quality. These ripening disorders are considered to be physiological in nature resulting from altered metabolism and disruption of normal ripening and senescence processes; what causes them is not known (Watkins, 2007).

In common with other fruit, grape berries also succumb to several ripening disorders such as bunch-stem necrosis, prolonged dehydration, sunburn, and berry shrivel (Hall et al., 2011; Keller, 2010; Krasnow et al., 2010). Of these ripening disorders, berry shrivel, as it is known in viticulture parlance, is a lesser known ripening oddity (Bondada et al., 2009; Krasnow et al., 2009), although there is a high possibility that it may have been afflicting grapevines for a long time but was not distinguished and hence neglected because of its close resemblance to bunch-stem necrosis. With no known causes but a remarkable effect in reducing fruit quality and yield (Hall et al., 2011; Krasnow et al., 2009), it poses a great concern to grape growers and wine makers worldwide. Both red and white cultivars are afflicted by berry shrivel (Bondada et al., 2009; Hall et al., 2011). However, there is no clear pattern as to its occurrence; berry shrivel occurs in a wide variety of soils and cultural and environmental conditions (Bondada et al., 2009). Consequently, there are no remedies to berry shrivel. The symptoms, osmotic behavior, and fundamental anatomical alterations at the cellular level need to be elucidated to determine the underlying mechanisms of berry shrivel. Moreover, organoleptic quality is the result of many morphophysiological and biochemical processes in fruit (Rančić et al., 2010). In view of that, first the gross and cellular-level symptoms and their extent are generally analyzed to document yield and quality losses whenever fruit crops are afflicted with physiological disorders (Watkins, 2007). The objective of this study was to elucidate the symptomatological, morphoanatomical, and osmotic characteristics of berry shrivel. Dissecting such features of this phenomenon will provide deeper insight into the mechanisms involved in the odd ripening behavior of berry shrivel and aid in the eventual development of suitable guidelines to minimize the incidences of berry shrivel.

\section{Materials and Methods}

Plant material. Experiments were conducted in commercial vineyards in the Horse Heaven Hills and Wahluke Slope American Viticultural Areas, WA (lat. 45 59' N, long. $119^{\circ} 32^{\prime}$ W). Mature own-rooted grapevines of cultivars Cabernet Sauvignon and Sémillon were used with vine-by-row spacing of $1.83 \times 2.74 \mathrm{~m}$ on a loamy fine sand. The rows were oriented north-south. Vines were trained to two trunks and a bilateral cordon and shoots were loosely vertically positioned. Vines were spur-pruned to 20 to 23 nodes/m of cordon and, in accordance with standard industry practice, were thinned to $\approx 20$ shoots/m at the beginning of bloom. Standard cultural practices were adopted to maintain healthy vines. These vineyards were chosen because they consistently developed berry shrivel year after year. During the season, vines were monitored regularly for berry shrivel symptoms by visually examining the clusters.
As soon as symptoms became apparent, vines and their clusters with berry shrivel were tagged for sampling and analyzing anatomical features and compositional attributes.

BERRY VOLUME, TOTAL SOLUBLE SOLIDS, OSMOTIC POTENTIAL, AND MINERAL NUTRIENTS. Healthy and afflicted clusters from the same vineyard were harvested, put in a zip-lock bag, and transported to the laboratory. Healthy clusters came from those vine rows that bore absolutely no shriveled clusters. Forty berries from healthy and berry shrivel clusters were removed and depediceled using a sharp razor blade. A known volume of water was recorded in a measuring cylinder. The berries were gently immersed in water, and the increase in volume resulting from displacement of water by 40 berries was recorded and used for calculating the volume of individual healthy and afflicted berries according to Archimedes principle. Total soluble solids of extracted mesocarp sap from healthy berries of healthy clusters, healthy-appearing berries from shriveled clusters, and shriveled berries from the same shriveled clusters were measured using a desktop refractometer (Kernco Industries, El Paso, TX). To measure $\psi_{\mathrm{S}}$, first the osmolality was measured using a vapor pressure osmometer (5500B; Wescor, Logan, UT) and converted to $\psi_{\mathrm{S}}(\mathrm{Y} \pi=-R T C$, where $R=8.3143 \mathrm{~J} / \mathrm{mol} / \mathrm{K}$ and $T=$ absolute temperature in Kelvin) as reported by Tilbrook and Tyerman (2008). A total of 33 berries (11 in each group) were measured. Potassium and calcium of whole berries were determined by a commercial laboratory using inductively coupled plasma spectroscopy (Soltanpour et al., 1996).

Light MICROSCOPY. To examine the gross external and internal morphological features of berries and seeds, berries were excised from healthy and afflicted clusters. Berries were then sectioned longitudinally through the center to examine the internal morphology of the pericarp. Seeds from healthy and afflicted berries were removed, washed with distilled water, and then air-dried. The seedcoat was gently fractured to reveal internal morphology. To examine the brush, the pedicles of the berries were gently pulled. Whole and sectioned berries and whole and fractured seeds were examined with a stereomicroscope (Stemi 2000-C; Carl Zeiss, Thornwood, NY) attached with a digital camera (DXM 1200C; Nikon Instruments, Melville, N Y), which was used for capturing digital images.

To examine the peduncle, samples were prepared by using standard free-hand sectioning technique as described by Ruzin (1999). All sections were cut using a new double-sided razor blade. Briefly, a leveling cut was made for the purpose of forming a right angle with the axis of the organ to ensure that the sections made were cross-sections. After each cutting, the cut section that collected on the blade was transferred to a drop of water on a slide and covered with a coverslip by lowering it at an angle onto the drop of water containing the sections for observation with epifluorescence microscopy (Axioskop 2 plus; Carl Zeiss) attached with a digital camera (DXM 1200C; Nikon Instruments).

Small rachis tissue samples were cut using a razor blade; subsequently, the tissues were fixed and preserved in formalinacetic acid-alcohol. The fixed tissues were dehydrated using the tertiary butyl alcohol series, infiltrated and embedded in paraffin, sectioned at $\approx 10 \mu \mathrm{m}$ with a microtome (MT 990; Boeckeler Instruments, Tucson, AZ), affixed to glass slides $(8 \times$ $3 \mathrm{~cm})$, and stained with Johansen's safranin $[1 \%(\mathrm{w} / \mathrm{v})$ dissolved in $50 \% \mathrm{EtOH}]$ and fast green $[0.2 \%(\mathrm{w} / \mathrm{v})$ dissolved in $95 \% \mathrm{EtOH}$ ] protocol (Ruzin, 1999). The staining procedure involved rehydration in descending strengths of alcohol, stain- 
ing with safranin, dehydration in ascending strengths of alcohol, and counterstaining with fast green. When staining was complete, a drop of Permount (Fisher Scientific, Fair Lawn, NJ) mounting medium was used to affix coverslips to the slides. Slides were placed under a compound microscope (Axioskop 2 plus; Carl Zeiss) attached with a digital camera (DXM 1200C; Nikon Instruments).

Crystal MORPhOlogy. Small drops of juice from a small slit made by a sharp razor blade at the distal end of a healthy berry and the pedicel-berry attachment region of de-pediceled berry shrivel berries were collected and placed on slides and covered with a coverslip and examined with a compound microscope (Axioskop 2 plus; Carl Zeiss) attached with a digital camera (DXM 1200C; Nikon Instruments).

SCAnning electron microscopy. Tissue samples from healthy canes and canes that bore berry shrivel clusters were cut using a razor blade, fixed in 3\% glutaraldehyde overnight, washed with $0.1 \mathrm{M}$ potassium phosphate buffer at $\mathrm{pH} 7.2$, and post-fixed in $2 \%$ osmium tetroxide overnight. Samples were then dehydrated in an ascending series of ethanols ending in $100 \%$ ethanol. The tissue samples were subsequently critical point-dried, coated with gold, and viewed with scanning electron microscopy (SEM; S-570; Hitachi Scientific Instruments, Mountain View, CA) using an accelerated voltage of $15 \mathrm{kV}$. Before using the SEM, the scope magnification was calibrated by photographing a gold grid and compared with a standard. The spot size was set toward the maximum diameter and minimum beam intensity with a standard working distance of $8 \mathrm{~mm}$.

Small pieces of the berry exocarp from the equatorial region were cut using a sharp razor blade. The tissue samples were fastened to aluminum specimen mounts and placed in a desiccator for air-drying the samples. Before viewing, the dried samples were coated with platinum. To observe epicuticular wax morphology, a focused ion beam (FIB)/SEM dual beam microscope of the microscopy facility located at the Environmental Molecular Sciences Laboratory-Pacific Northwest National Laboratory, Richland, WA, was used. The mounted samples were transferred to a dual-beam system for FIB/SEM operation (Helios NanoLab DualBeam; FEI Corp., Hillsboro, OR). SEM imaging was performed by means of the field emission gun electron column available in the same system using a SEM beam voltage of $5 \mathrm{kV}$ with a $1-\mathrm{nm}$ spot size.

Cell viability (Membrane InTegrity). Cell viability was assessed first by staining cut surfaces of berries with 5,(6)carboxyfluorescein diacetate (5,6-CFDA SE) and then observing stained berries with confocal laser scanning microscopy (CLSM). Stock 5,6-CFDA SE was made up as follows: $1 \mathrm{~mL}$ of dimethyl sulphoxide was added to $100 \mathrm{mg}$ of 5,6-CFDA SE (Invitrogen, Carlsbad, CA). Thereafter, $1-2 \mu \mathrm{L}$ of the stock was added to polypropylene vials containing $1 \mathrm{~mL}$ distilled water. Stock and working strength 5,6-CFDA SE was kept foilwrapped and stored at $-4{ }^{\circ} \mathrm{C}$ until needed. Healthy and berry shrivel berries were cut longitudinally through the median into two equal halves, and each half was stained with CFDA solution for $15 \mathrm{~min}$.

A CLSM (LSM 510; Carl Zeiss) was used to image fluorescence as quickly as possible to minimize the dye loss. The fluorescence of CFDA was analyzed by excitation at $488 \mathrm{~nm}$, and emission was detected at a bandpath of 505-570 nm. The fluorescence of cells was captured using a digital camera.

SeEd Germination. Seed germination followed the method descried by Hall et al. (2011). Seeds of berries from healthy clusters and berry shrivel berries and healthy-appearing berries from shriveled clusters were removed and washed with and then placed in distilled water. Sinker seeds with nucellus and endosperm (Ebadi et al., 1996) were air-dried and weighed using three 10 -seed replicates for each cluster. Seeds were stratified at $2{ }^{\circ} \mathrm{C}$ for several months, then soaked in deionized water for $24 \mathrm{~h}$, surface-sterilized by submerging for $5 \mathrm{~min}$ in $1 \%$ $\mathrm{NaOCl}$, and rinsed three times with sterile deionized water. Thirty seeds per cluster were placed on moist filter paper in a petri dish, covered and sealed with Parafilm (Fisher Scientific), and incubated at $25^{\circ} \mathrm{C}$ in the light for $21 \mathrm{~d}$ to observe seed germination. The germinated seeds were examined with a stereomicroscope (Stemi 2000-C; Carl Zeiss) attached with a digital camera (DXM 1200C; Nikon Instruments).

All quantitative data were analyzed by one-way analysis of variance using SPSS (Version 11; IBM Corp., Armonk, NY).

\section{Results}

Physical and Compositional Characteristics. Berry shrivel berries along with the berries that appeared to be healthy in afflicted clusters had reduced concentrations of total soluble solids [TSS (sugars)] (Table 1). Unlike healthy spherical berries, the pericarp in disordered berries shriveled causing concomitant reductions in fresh weight and volume (Table 1). Berry fresh weight of healthy-appearing and berry shrivel berries were significantly lower than the fresh weights of healthy berries (Table 1). Conversely, there were no significant differences in seed weight among the three types of berries; i.e., healthy berry, healthy-appearing berry from berry shrivel cluster, and berry shrivel berry (Table 1). A strong negative relationship existed between $\psi_{\mathrm{S}}$ and TSS of the mesocarp sap (Fig. 1A). The amount of potassium in healthy berries was significantly higher than in either berry shrivel berries or healthy-appearing berries from afflicted clusters (Fig. 1B). Conversely, there was no significant difference in calcium amounts among the three types of berries (Fig. 1B).

MorphoANATOMy OF HEALThy BERRIES. A fundamental analysis of morphoanatomy of healthy berries, canes, and the cluster framework is crucial because such details aid in gaining a better understanding of the developmental anomalies manifested as structural modifications when grape berries deviate

Table 1. Physical and compositional properties of berry shrivel and healthy 'Cabernet Sauvignon' grape berries ( $\mathrm{n}=10$ clusters).

\begin{tabular}{lcccr}
\hline $\begin{array}{l}\text { Berry } \\
\text { type }\end{array}$ & $\begin{array}{c}\text { Sugar content } \\
{[\text { mean } \pm \text { SE }(\mathrm{mg} / \text { berry })]}\end{array}$ & $\begin{array}{c}\text { Berry fresh wt } \\
{[\text { mean } \pm \text { SE }(\mathrm{g} / \text { fruit })]}\end{array}$ & $\begin{array}{c}\text { Berry vol } \\
{\left[\text { mean } \pm \text { SE }\left(\mathrm{cm}^{3}\right)\right]}\end{array}$ & $\begin{array}{c}\text { Seed wt } \\
{[\mathrm{mean} \pm \mathrm{SE}(\mathrm{mg} / \mathrm{seed})]}\end{array}$ \\
\hline $\mathrm{HB}$ & $269 \pm 6.5 \mathrm{c}^{\mathrm{y}}$ & $1.19 \pm 0.05 \mathrm{c}$ & $1.05 \pm 0.04 \mathrm{c}$ & $26 \pm 1.62 \mathrm{a}$ \\
$\mathrm{HAB}$ & $178 \pm 5.9 \mathrm{~b}$ & $0.94 \pm 0.03 \mathrm{~b}$ & $0.88 \pm 0.03 \mathrm{~b}$ & $26 \pm 0.59 \mathrm{a}$ \\
$\mathrm{BS}$ & $53 \pm 2.5 \mathrm{a}$ & $0.41 \pm 0.07 \mathrm{a}$ & $0.39 \pm 0.06 \mathrm{a}$ & $25 \pm 1.08 \mathrm{a}$ \\
\hline
\end{tabular}

$\overline{{ }^{\mathrm{z}} \mathrm{HB}}=$ healthy berry from healthy cluster; HAB $=$ healthy-appearing berry; BS = berry shrivel berry from clusters afflicted with berry shrivel.

${ }^{\mathrm{y}}$ Means within a column followed by the same letter are not significantly different by Holm-Sidak test at $P<0.05$. 

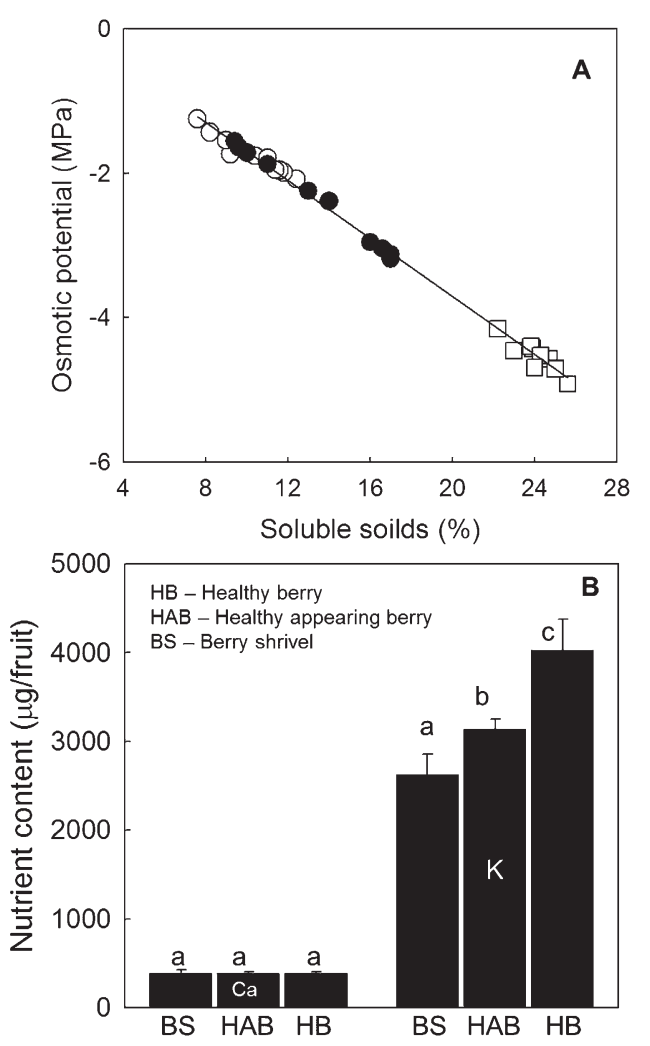

Fig. 1. (A) Mesocarp sap osmotic potential $\left(\psi_{\mathrm{S}}\right)$ as a function of sugars showing a negative relationship resulting from healthy 'Cabernet Sauvignon' grape berries and berries afflicted with berry shrivel $\left(P<0.001, y=-0.20 x+0.31, r^{2}\right.$ $=0.99) ; \square=$ healthy berries; $\bullet=$ healthy appearing berries from berry shrivel cluster; $\bigcirc=$ berry shrivel berry. (B) Amount of potassium and calcium per fruit in healthy 'Cabernet Sauvignon' grape berries and berry shrivel berries. Within a nutrient, bars (mean $\pm \mathrm{SE}$ ) sharing a common letter are not significantly different $(P<0.05)$.

from the normal course of ripening events. As per this premise, clusters from healthy vines were analyzed wherein the berries were borne on a pyramidal cluster framework with a proximalto-distal decrease (Fig. 2A). Berries from healthy 'Cabernet Sauvignon' clusters were spherical, turgid, and firm yet soft to the touch and elastic with dark pigmentation of the exocarp (Fig. 2A). Anatomically, the mature ovary wall of healthy berries was juicy and thick in which three tissue strata in a bilateral symmetry could be distinguished: the outer stratum, which concentrated the red pigments (anthocyanins) of the berryexocarp (skin); the thick soft stratum below it-mesocarp (flesh), which accumulated colorless juice in the parenchyma cells; and the membranous inner stratum-endocarp (Fig. 2B). The three strata collectively made up the pericarp wherein the seeds (two to four) were housed in two locules, up to two in each locule in the center of the mesocarp. One of the seeds is shown in Figure 2B.

The mesocarp was permeated by a vascular system that consisted of a central network, which approximately paralleled the central axis ending at the distal pole of the berry (axial vascular bundle) (Fig. 2B) and a highly ramified reticulate system diverging from the base of the axial vascular bundles that permeated the outer tangential surfaces of the exocarp (dorsal vascular bundle) (Fig. 2B-C) and then again merged with the corresponding axial vascular bundles a short distance below the fruit apex (Figs. 2B and 2D). The dorsal vascular system separated the mesocarp into inner and outer zones. The ovule in each locule was supplied by a vascular strand derived from the central system (Fig. 2B). Examination of the receptacle-berry interface revealed that the vascular system at the base of the berry consisted of a ring of several strands (Fig. 3A), which entered from the pedicel (Fig. 3B).

The viability of mesocarp cells was checked by their ability to accumulate fluorescein as a result of the enzymic cleavage of carboxyfluorescein and the fluorescence was observed with CLSM. Accordingly, the parenchymatous mesocarp cells of healthy berries were oblong to oval-shaped and fully turgid as demonstrated by the emission of bright green fluorescence (Fig. 2E). Evidently, the vacuole bounded by its tonoplast occupied most of the cell volume pressing the cytoplasm into a thin layer against the cell membrane; consequently, fluorescence was observed as a thin oblong illumination. Compositional analysis (Table 1; Fig. 1) indicated that the vacuole acted as the repository of cell sap, which primarily contained sugary soluble solids at ripening.

At the proximal end of the berry, a well-defined brush (i.e., the cone-shaped opaque mesocarp tissue with proximal ventral vascular bundles, which remains attached to the pedicel as the pedicel and berry are pulled apart) existed within the mesocarp (Fig. 2F-G). Flanking the brush, the pear-shaped geometry of seeds in the locules had rough surface morphology marked by a pair of distinctive ventral infolds (also known as fossettes, seed folds, or rumination ingrowth) (Fig. 2H) and a centrally positioned dorsal chalaza knot, which was sunken and circular to oval in shape (Fig. 2I). Between the fossettes, a prominent longitudinal ridge, known as a keel or karina, existed (Fig. 2H). From the hilum, a raphe lengthened along the keel passing through the apical notch ending with the chalaza on the dorsal side (Fig. 2H-I). The beak varying in length, thickness, and the sharpness of the angle at the hilum was either straight or curved and rough or wrinkled or smooth (Fig. 2H-I). On the opposite end of the beak, there was a notch as a small indentation. The seeds had a well-developed embryo whose surface consisted of polygonal cells (Fig. 2J-K). A cross-section of the seed revealed well-developed integuments that surrounded the endosperm and embryo (Fig. 2L). After germination, the embryo first developed a hypocotyl before developing into a seedling (Fig. 2M).

MORPHOANATOMY OF BERRY SHRIVEL BERRIES. Berries afflicted with berry shrivel lost their sphericity and became irregular-shaped, flaccid, and soft (Fig. 3C-D). The flaccidity folded the pericarp causing undulated periphery wherein the exocarp wrinkled and pulled away from the receptacle forming deep grooves into the mesocarp (Fig. 3D, inset). Visually, such berries were reminiscent of a deflated soccer ball. In 'Cabernet Sauvignon', these berries often rather remained pink (Figs. 4A and $4 \mathrm{C}$ ); however, the extent of pigmentation varied considerably even within the same cluster (Figs. 3D, 4A, and 4D), whereas other berries were indistinguishable from healthy berries (Fig. 3D). Although the berries were shriveled, their support system involving the rachis, peduncle (stalk of the cluster), and pedicel (stalk of the fruit) remained chlorophyllous throughout the growing season (Figs. 3C, 3D, and 4A) similar to healthy clusters. However, necrotic cells developed in the exocarp that encircled the interface between pedicel (Fig. 4E) and the berry (Fig. 4F). Similar to healthy berries, the seeds were the most conspicuous structures as revealed by the longitudinal section of berry shrivel berry. Furthermore, their morphoanatomy was identical to the healthy seeds. This is why only the seeds from healthy berries are shown in Figures $2 \mathrm{H}$ and 2I. In sharp contrast, the bulk of the mesocarp was watery and 

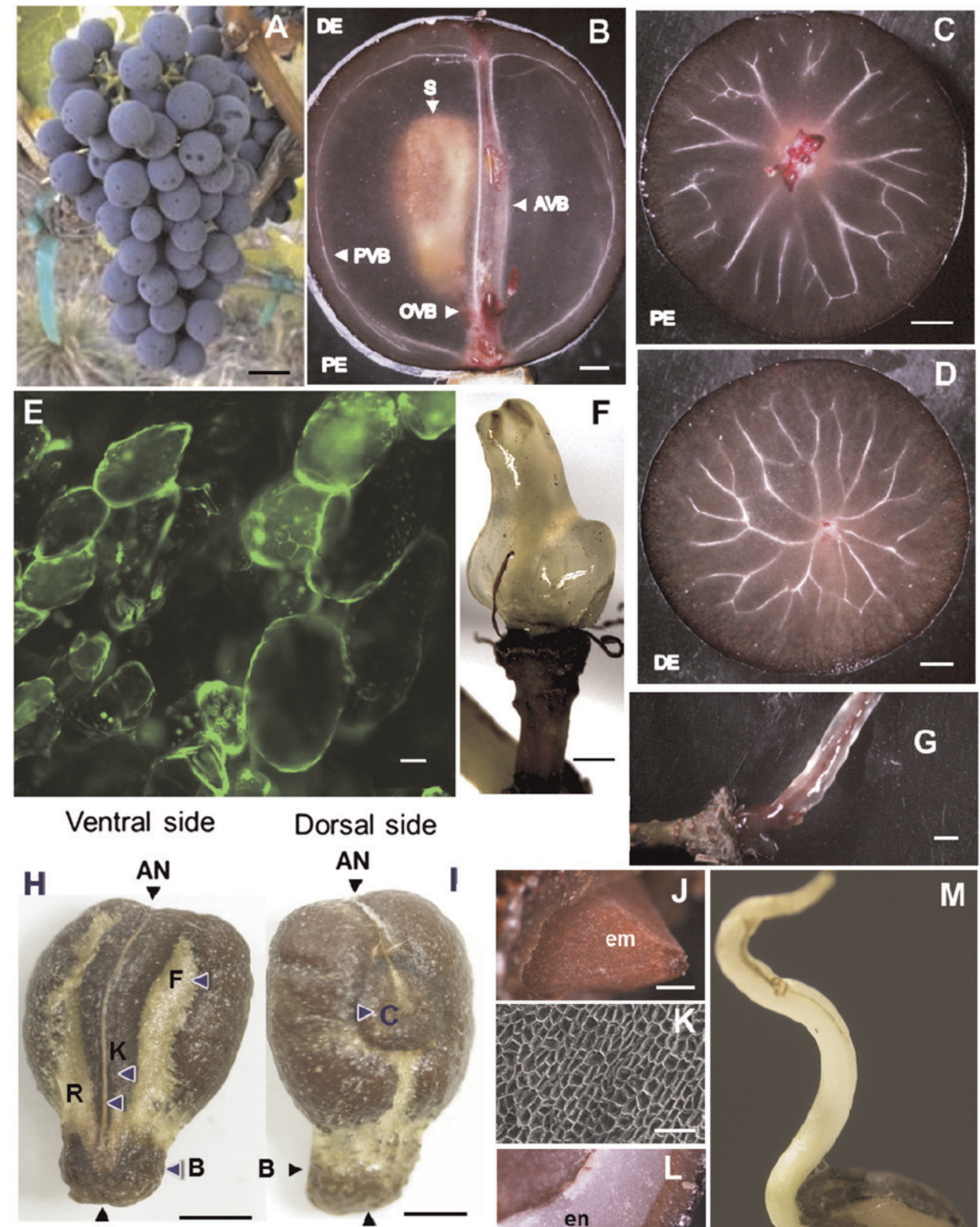
$\mathbf{H}$
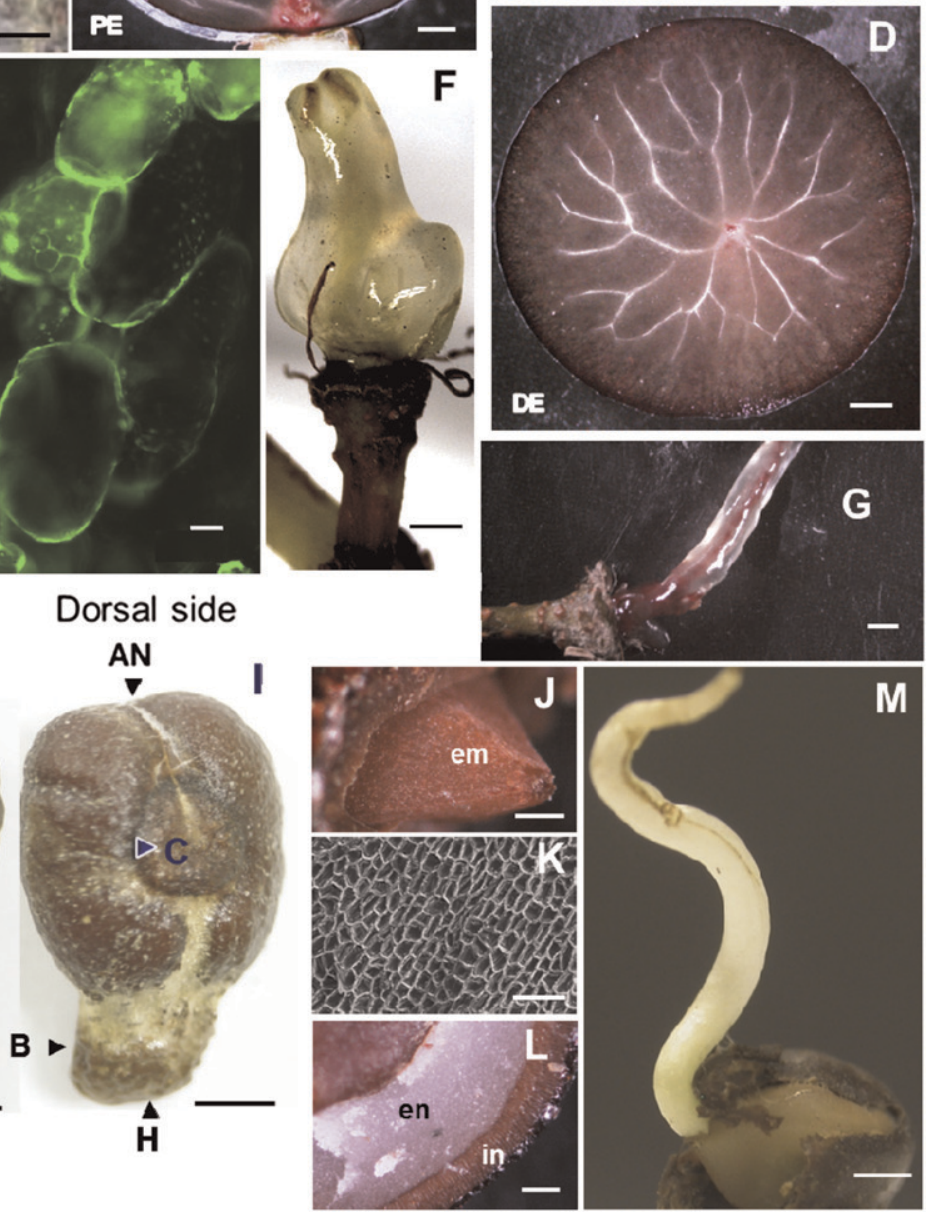

Fig. 2. Photograph of (A) a healthy 'Cabernet Sauvignon' grape cluster showing spherical berries attached to rachis with healthy pedicels; (B) a stereomicrograph showing a longitudinal section of a healthy 'Cabernet Sauvignon' berry with bilateral symmetry of pericarp embedded with axial, peripheral, and ovular vascular tissues and a seed; stereomicrographs of $(\mathbf{C})$ healthy 'Cabernet Sauvignon' berry showing the highly ramified peripheral or dorsal vascular bundle at the proximal end and (D) peripheral bundle united with the axial vascular bundle at its distal end; (E) a confocal laser scanning microscopy image of healthy 'Cabernet Sauvignon' berry mesocarp showing green fluorescence as thin oblong illumination from the parenchyma cells; (F) a photograph of brush of a healthy white grape cultivar; $(\mathbf{G})$ brush and ventral vascular bundles within the septum of a healthy 'Cabernet Sauvignon' berry; (H) ventral and (I) dorsal surfaces of a healthy 'Cabernet Sauvignon' berry seed; (J) a stereomicrograph of healthy 'Cabernet Sauvignon' berry seed showing the proximal end of the embryo; (K) a scanning electron micrograph (J) showing polygonal surface morphology; (L) a stereomicrograph of the transverse section of a healthy 'Cabernet Sauvignon' seed showing integuments and endosperm; and (M) a photograph of a germinated healthy 'Cabernet Sauvignon' seed showing embryonic axis (hypocotyl). Scale bars: $10 \mathrm{~mm}(\mathbf{A}), 1 \mathrm{~mm}(\mathbf{B}-\mathbf{D}, \mathbf{G}-\mathbf{I}), 50 \mu \mathrm{m}(\mathbf{E}), 250$ $\mu \mathrm{m}(\mathbf{F}), 250 \mu \mathrm{m}(\mathbf{J}), 50 \mu \mathrm{m}(\mathbf{K}), 250 \mu \mathrm{m}(\mathbf{L})$, and $250 \mu \mathrm{m}(\mathbf{M}) . \mathrm{AN}=$ apical notch; AVB = axial vascular bundle; B = beak $\mathrm{C}=$ chalaza DE $=$ distal end $\mathrm{F}=$ fossettes $; \mathrm{H}=$ hilum; $\mathrm{K}=$ karina; $\mathrm{OVB}=$ ovular vascular bundle; $\mathrm{PE}=$ proximal end; $\mathrm{PVB}=$ peripheral vascular bundle; $\mathrm{R}=$ raphe; $\mathrm{S}=$ seed.

collapsed loosening the taut vascular system that was firmly embedded in the mesocarp (Fig. 4G). As a result, the brush lacked the opaque flesh but had vascular strands torn from the inside of the berry (Fig. 4H). The collapsed mesocarp did not emit any fluorescence when incubated with CFDA (Fig. 4I) indicating that the cells were no longer viable. Furthermore, the turbid mesocarp juice was replete with crystals of calcium oxalate having distinct geometrical shapes. They mainly exhibited face forms of pinacoid; i.e., two-faced form made up of two parallel faces (Fig. 5A-5E). Some of them were rhomboid (Fig. 5A-B) and variants of rhomboid (Fig. 5C); others were strongly elongated forming rectangular columns with narrow pinacoids, which were roofed on both ends by prismatic geometry; i.e., styloids (Fig. 5D). There were also transition forms between styloids and raphides (Fig. 5E). Such crystals were not observed in the juice of healthy berries. By contrast, the epicuticular wax morphology was indistinguishable from that of healthy berries; in both cases, wax occurred as upright platelets consisting of reticulum of microfilaments (Fig. 5F-G).

Anatomy OF CANE AND INFLORESCENCE FRAMEWORK. The anatomy of cane internodes showed tissue structural patterns that were typical of liana stems (Fig. 6A-B). On their exterior surface, canes had a brownish bark comprising dead epidermis, cortex, and part of the primary phloem, which was indicative of periderm formation and secondary growth of circumferential expansion through the activities of phellogen and vascular cambium, respectively. Below the bark lay the periderm followed by the vascular region consisting of abaxial (centrifugal) secondary phloem and adaxial (centripetal) secondary xylem (Fig. 6A-B). In this architecture, the phloem was composed of rays that occurred in alternate radial blocks and two types of tissues that occurred as alternate tangential bands, a hard phloem band consisting of fibers that provide structural support, and a soft phloem band consisted of sieve tubes (Fig. 6B), which perform the actual transport of the phloem sap. The hard phloem band was narrow and dense, whereas the soft phloem band was wider with relatively large cells (Fig. $6 \mathrm{~B})$. The phloem was subepidermally capped by a ridge of fiber cells (Fig. 6B). The xylem tissue, which transports soil water and 

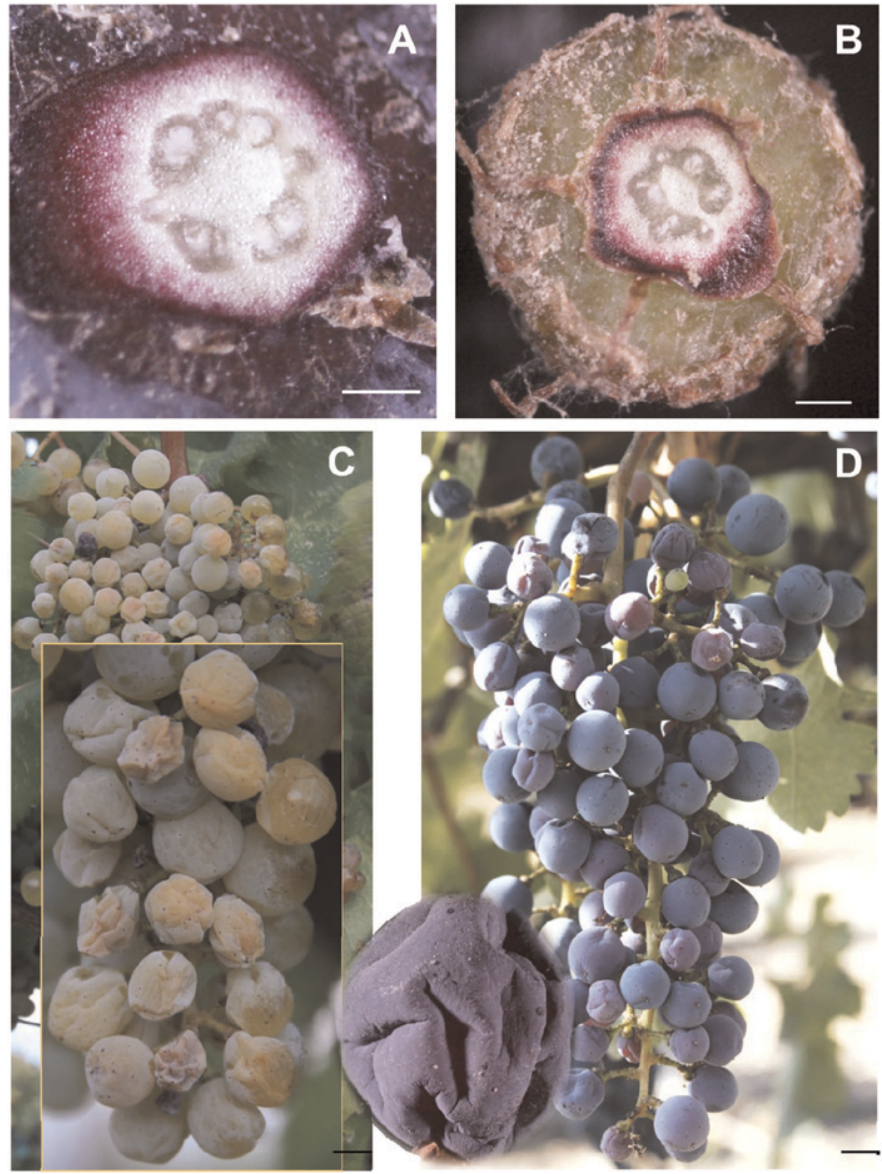

Fig. 3. Stereomicrographs of 'Cabernet Sauvignon' grape berry-receptacle interface of (A) receptacle from a healthy berry showing exocarp boundary firmly attached to tissues surrounding the vascular bundles and (B) vascular bundles at the distal end of pedicel; photographs of grape clusters of (C) 'Sémillon' and (D) 'Cabernet Sauvignon' afflicted with berry shrivel (inset: a flaccid berry showing wrinkling of exocarp). Scale bars: $500 \mu \mathrm{m}$ (A-B), $10 \mathrm{~mm}(\mathbf{C}-\mathbf{D})$.

minerals to the leaves, was composed of radially alternating blocks of parenchyma cells (rays) and a longitudinal system of cells that consisted of vessels, fibers, and parenchyma cells (Fig. 6A). The vessels are the actual conduits for transporting water and solutes; the narrow fibers with thick secondary cell walls among vessels provide structural support; and xylem parenchyma cells function in storage (Fig. 6A).

Among the three xylem tissues, vessels were the largest visible structures; they were circular in shape with open lumens occasionally in groups of two or three but mostly occurring singly as opposed to the layered configuration of phloem tissues that were scattered in clusters among the xylary fibers and separated by radiated bands of parenchyma cells (Fig. 6A). Because of their similarity in structural geometry, the secondary xylem was diffusely porous. With one exception, the shoots that bore the clusters of berry shrivel berries were analogous to healthy vines in terms of anatomy and morphology. The exception was that some of the xylem vessels in berry shrivel canes exhibited early stages of tylosis (Fig. 6C). No tylosis was observed in canes of healthy shoots. With the exception of comparatively smaller xylem vessels of the inflorescence framework, the anatomy of peduncle, rachis, and pedicel was similar to that of canes in both healthy clusters and clusters afflicted with berry shrivel with outer turgid epidermal and cortical cells followed by a well-developed vascular system (Fig. 6D-F).

\section{Discussion}

This study characterized key compositional (Fig. 1) and morphoanatomical (Figs. 2-5) similarities and differences between grape berries from healthy clusters and clusters affected by a ripening disorder known as berry shrivel. The pericarp remained intact in healthy berries (Fig. 2A-D) indicating that the mesocarp maintained turgid and viable parenchyma cells throughout berry growth and ripening. This confirms recent reports of maintenance of membrane integrity; i.e., cell viability in ripening grape berries (Fuentes et al., 2010; Krasnow et al., 2008; Tilbrook and Tyerman, 2008), which is a prerequisite to berry growth and water relations. For instance, fruit grow by the flux of water and solutes into the expanding mesocarp cells including transport through the pedicel, phloem unloading, and regulation of the osmotic and hydrostatic pressure of cells (Boyer and Silk, 2004). Conversely, the mesocarp was collapsed in berries affected by berry shrivel (Figs. 3C, 3D, and 4I), which was associated with death of parenchyma cells as also reported previously (Krasnow et al., 2008). This explains the off-flavor that berry shrivel berries often develop (Bondada et al., 2009; Hall et al., 2011) because development of unwanted flavor and aroma compounds do not occur until there is loss of membrane integrity and loss of cell compartmentalization (Gonzalez et al., 2010). Furthermore, Fuentes et al. (2010) observed a linear relationship between mesocarp tissue vitality and the degree of shrivel late in ripening in berries from 22 cultivars, which renders support to the premise that a mechanistic link exists between tissue vitality and water relations of berry (Keller et al., 2006; Tilbrook and Tyerman, 2008). In view of that, cell death renders the cell membranes non-selective so that the low $\psi_{\mathrm{S}}$ of the cell sap can no longer counter tensions within the cell walls and tracheary elements of the berry, and water could flow from berry to vine. Loss of membrane integrity also occurs during ripening of other fruit such as saskatoon [Amelanchier alnifolia (L.) Nutt. (Rogiers et al., 1998)], tomato [Solanum L. (Chen et al., 2004)], and kiwifruit [Actinidia deliciosa (A. Chev.) C.F. Liang et A.R. Ferguson var. deliciosa cv. Hayward (Zhang et al., 2006)]. These findings demonstrate that regardless of the origin of shrivel, shriveling of the pericarp occurs after cell death in the mesocarp. What might have caused membrane damage could not be ascertained from this study; however, such loss of membrane integrity has been linked to both peroxidation of membranes and depletion of energy, which is essential for maintenance of membrane form and function (Trippi et al., 1989). Because grape berries are strong sink for primary metabolites essential for plant survival and of course for commercial importance and the fact that they experience a burst of reactive oxygen species (ROS) during veraison (Pilati et al., 2007), it is highly possible that either there was overproduction of cytotoxic ROS or berry shrivel berries totally failed to develop the complex enzymatic antioxidative systems such as catalase, peroxidase, and superoxide dismutase. These hypotheses will need to be tested in future studies.

In addition to cell death, the present study revealed that the collapse of the mesocarp was associated with displacement of the berry vascular systems (Fig. 4G). Apparently, the reticulated 

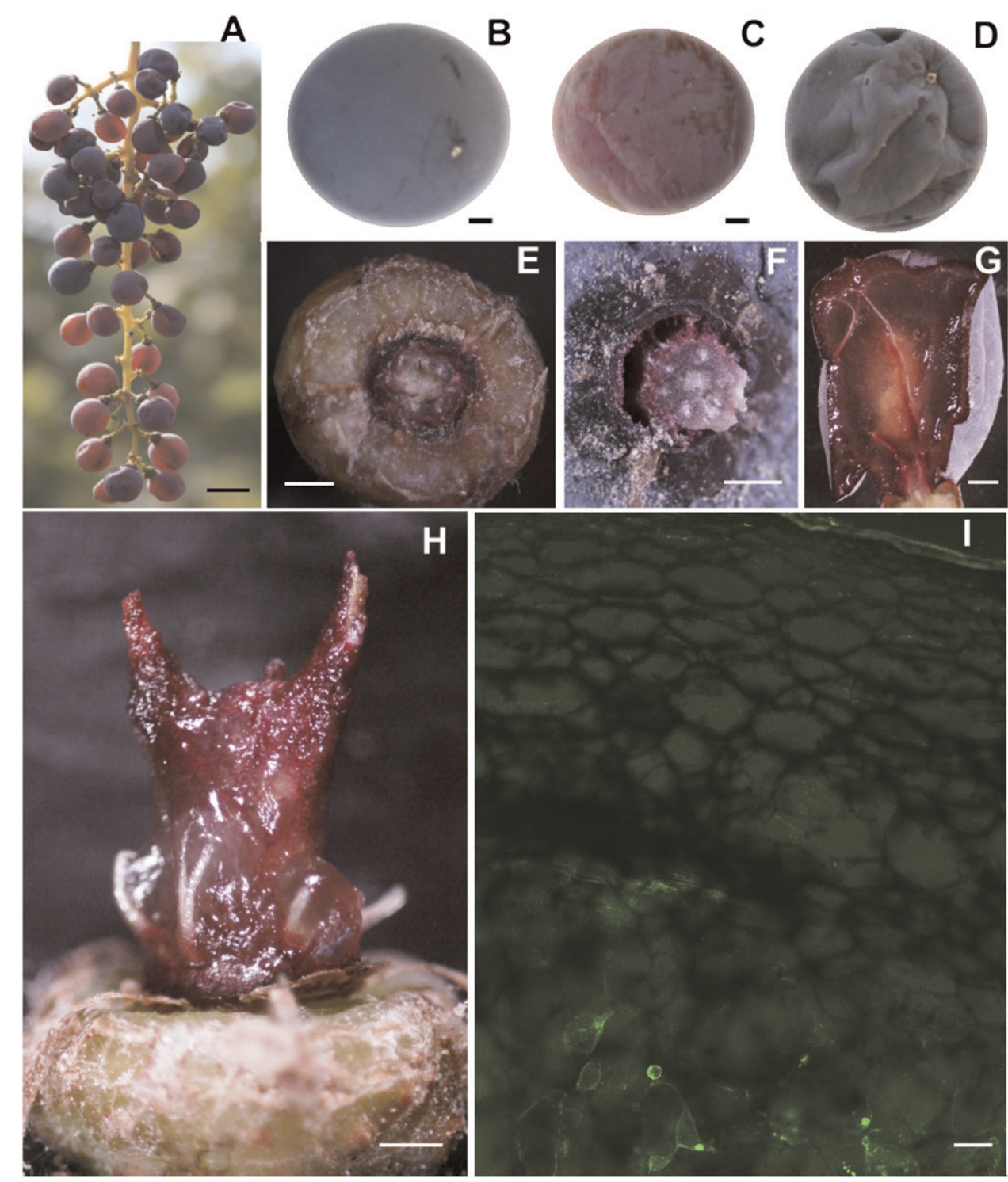

Fig. 4. Photographs of (A) a 'Cabernet Sauvignon' grape cluster afflicted with berry shrivel showing berries of reduced color interspersed throughout the cluster; (B) a healthy-appearing 'Cabernet Sauvignon' berry; (C) a flaccid 'Cabernet Sauvignon' berry with reduced color; (D) a flaccid 'Cabernet Sauvignon' berry with welldeveloped color; stereomicrographs of 'Cabernet Sauvignon' berry afflicted with berry shrivel showing (E) receptacle surface, $(\mathbf{F})$ necrosis of tissues between the exocarp boundary and the vascular cylinders causing an annular crack; (G) a longitudinal section of a berry shrivel 'Cabernet Sauvignon' berry with collapsed mesocarp and disorganized placement of vascular cylinders; $(\mathbf{H})$ a longitudinal section of a berry shrivel 'Cabernet Sauvignon' berry without any brush but shows broken remnants of peripheral and axial vascular bundles; and (I) a confocal laser scanning microscopy image of mesocarp from berry shrivel 'Cabernet Sauvignon' berry showing dead parenchyma cells as evident from a lack of green fluorescence. Scale bars: $10 \mathrm{~mm}(\mathbf{A}), 1 \mathrm{~mm}(\mathbf{B}-$ D, G), $500 \mu \mathrm{m}(\mathbf{E}), 500 \mu \mathrm{m}(\mathbf{F}), 500 \mu \mathrm{m}(\mathbf{H})$, and $50 \mu \mathrm{m}(\mathbf{I})$.

pattern of the dorsal vascular system in healthy berries (Fig. 2B-D) arises from the immense expansion of the parenchymatous mesocarp cells during berry growth that elongates these strands laterally and causes them to appear as a network of strands, although at the same time, enlargement of the mesocarp cells isolates the dorsal vascular system from the axial vascular system (Fig. 2B). Furthermore, the berry shrivel berries lacked the opaque brush (Fig. 4H) present in the healthy berries (Fig. $2 \mathrm{~F}-\mathrm{G})$, which may be a further indication of cell death and tissue collapse. The absence of brush in combination with the fragile tissue structure at the berry-pedicel interface weakened the pedicel attachment, which explains the berry drop that is
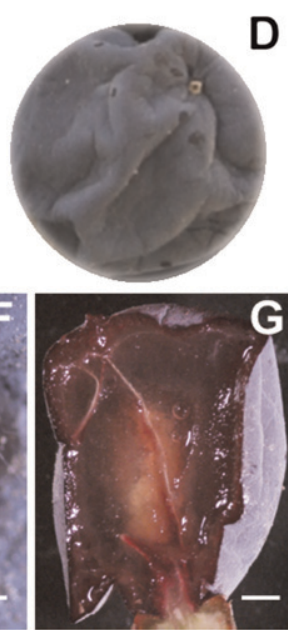

sometimes observed when afflicted clusters are touched by hand or machinery.

Conversely, healthy berries developed typical characteristics of a true berry; i.e., a fleshy indehiscent fruit with bilateral symmetry of tissues organized in three strata: exocarp, mesocarp, and endocarp, collectively known as the pericarp (Bondada, 2011; Bondada et al., 2005; Hardie et al., 1996), which represents the culmination of a successful completion of all events of flower formation followed by pollination and fertilization and the double sigmoid course of berry development (Coombe, 1976). The mesocarp of healthy berries had oval-shaped, viable, and turgid parenchyma cells (Fig. 2E). Such characteristics indicate that the plasma membranes are semipermeable and the large negative $\psi_{\mathrm{S}}$ of the mesocarp cells balances the apoplast pressures and the tension generated in vine xylem by leaf transpiration (Keller et al., 2006; Tilbrook and Tyerman, 2008). Moreover, use of CFDA in this study coupled with high-resolution imagery permitted visualizing osmotic properties and shape of the cells. For instance, it can be clearly seen that the mesocarp cells were compartmentalized enclosing a thin layer of cytoplasm between tonoplast and plasma membrane (Fig. 2E). This is possible only when the cells maintain the structural integrity of their bounding membranes (Diakou and Carde, 2001) and is consistent with a greatly expanded vacuole that accounts for most of the growth of the grape berries through water influx driven by solute accumulation (Keller, 2010; Ojeda et al., 1999). The predominance of the vacuole over the cytoplasm and other cell organelles, which represent less than $1 \%$ of cell volume at ripening (Diakou and Carde, 2001), suggests that transcellular water exchange may depend on the permeability of two membranes in series, the plasma membrane and the tonoplast (Maurel et al., 1997).

In the decompartmentalized mesocarp cells of berry shrivel berries, a wide spectrum of calcium ( $\mathrm{Ca}$ ) oxalate crystals became loose (Fig. 5A-E), which generally remain in close contact with cytoplasm (Frey-Wyssling, 1981). The intriguing aspect of crystal formation in this study was that druse (star-shaped) crystals, one of the two crystalline aggregations (the other one is raphide) and the crystalline norm in grapes (DeBolt et al., 2004), were not observed in the pericarp of berry shrivel berries. 

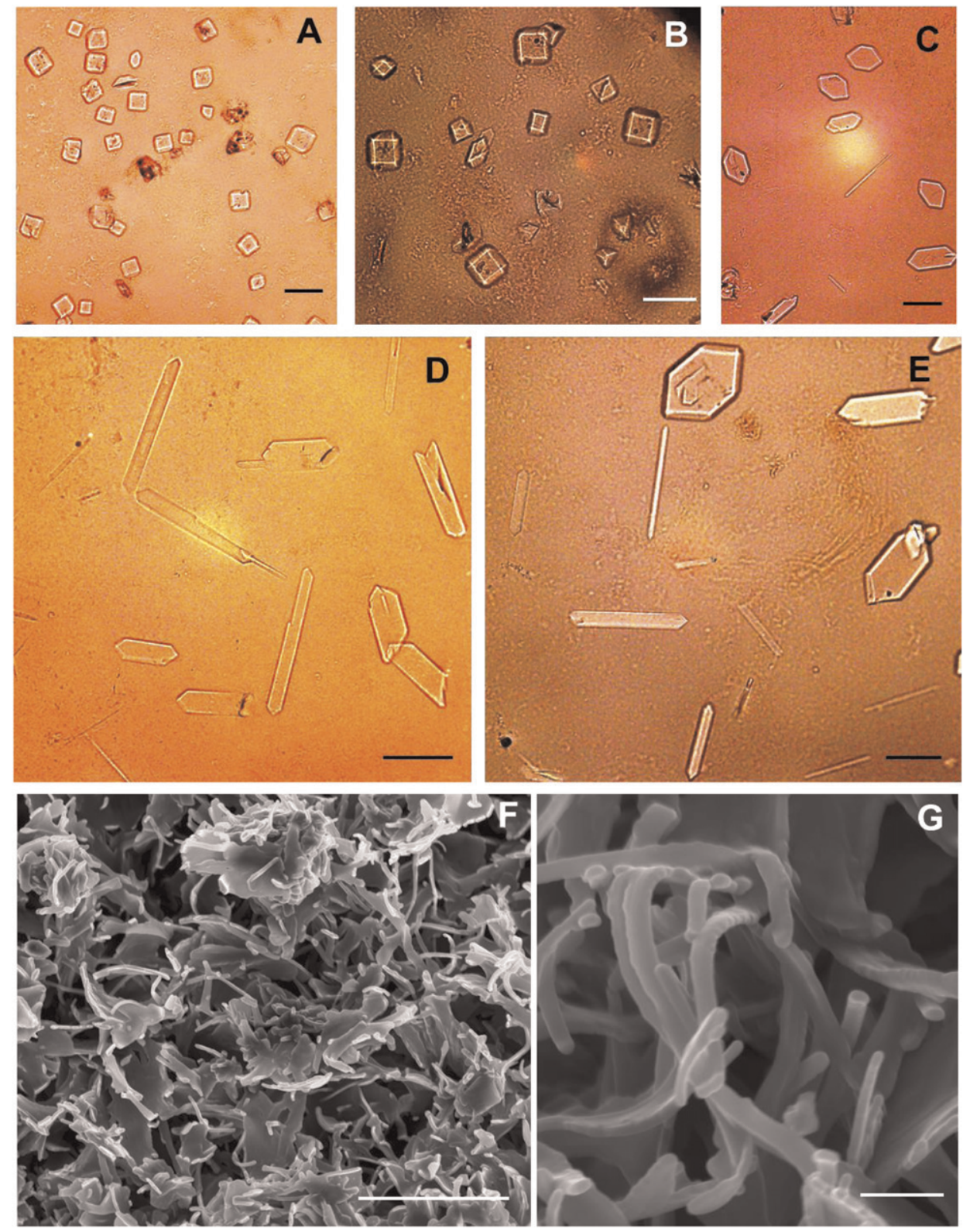

Fig. 5. Light microscopy images of calcium oxalate crystals with dominating pinacoid from the mesocarp juice of berry shrivel 'Cabernet Sauvignon' grape berries: (A) rhomboid-shaped crystals, (B) rhomboids, $(\mathbf{C})$ variants of rhomboid crystal, (D) rod-shaped styloid crystals, (E) transition forms between raphide and styloid crystals; scanning electron micrographs of (F) epicuticular wax from 'Cabernet Sauvignon' berry afflicted with berry shrivel showing wax platelets, and (G) high magnification of wax platelets (F) showing reticulate microfilaments. Scale bars: $100 \mu \mathrm{m}(\mathbf{A}), 50 \mu \mathrm{m}(\mathbf{B}-\mathbf{E}), 3 \mu \mathrm{m}(\mathbf{F}), 500 \mathrm{~nm}(\mathrm{G})$.

Instead, masses of non-druse crystals (e.g., styloids, rhomboids, etc.) were observed (Fig. 5A-E). Similar non-druse crystals have been reported in the epidermal subcuticular areas of Dracaena sanderiana hort sander ex M.T. Mast., an angiosperm species (Pennisi et al., 2001). Thus, it appears that the formation of these non-druse crystals is not a biologically controlled but rather a biologically induced stochastic process of biomineralization involving extracellular precipitation of calcium oxalates. However, although it seems likely that death of phloem cells in the cluster rachis (Hall et al., 2011) causes the cessation of sugar and potassium accumulation observed here and elsewhere (Knoll et al., 2010; Krasnow et al., 2009), it is not clear why this should

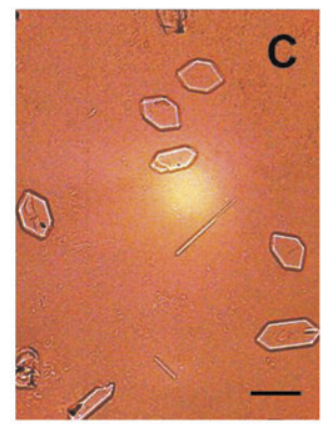

lead to cell death in the mesocarp or why crystals precipitated in such forms. These are evident questions for future research.

Despite the marked differences in berry morphology and mesocarp structure and composition, the seeds of berry shrivel berries were pearshaped and brown-colored with a rough surface morphology just like the ones in healthy berries (Fig. 2H-I). This occurs when grape seeds develop a tough and dry integument mostly consisting of dead cells and a thin-walled epidermal cells (Cadot et al., 2006), whereas browning and hardening of seeds are associated with oxidation of phenolics (Keller, 2010). These seeds were as viable as seeds from healthy berries as evident from the elongation of the embryonic axis (Fig. 2M). Clearly, seed development and maturity either had advanced enough by the time berry shrivel initiated or their development was immune to the events associated with the altered fruit ripening process that culminated in the collapse of the mesocarp. Grape seeds attain full maturity in terms of embryo development by veraison (Hardie et al., 1996; Keller, 2010), and the first symptoms of berry shrivel generally do not appear until veraison or later (Hall et al., 2011; Knoll et al., 2010; Krasnow et al., 2009). So, it remains to be seen whether or how seed development controls the incidence of physiological disorders. Furthermore, epicuticular wax platelets (Fig. 5F-G) remained unaffected by berry shrivel indicating that their synthesis and deposition are completed by the time symptoms become apparent. These results suggest that the water loss from berries that is associated with this disorder is not the result of alteration of the epicuticular wax structure. Tyloses were observed in xylem vessels of some of the canes that bore berry shrivel clusters (Fig. 6C). Because elimination of the cluster-shoot xylem assembly did not trigger any symptoms in the berries (Hall et al., 2011), it seems unlikely that tylosis of vessels in the cane would have led to berry shrivel. Nonetheless, it is possible that rachis cell death observed in berry shrivel clusters (Hall et al., 2011) may have triggered a wound response in the shoot that could have led to tylosis (Sun et al., 2008).

The linear relationship between sugars and $\psi_{\mathrm{S}}$ (Fig. 1) as also observed in a previous study for the 'Cardinal' grapevine cultivar (Matthews et al., 1987) indicated that the increase in 


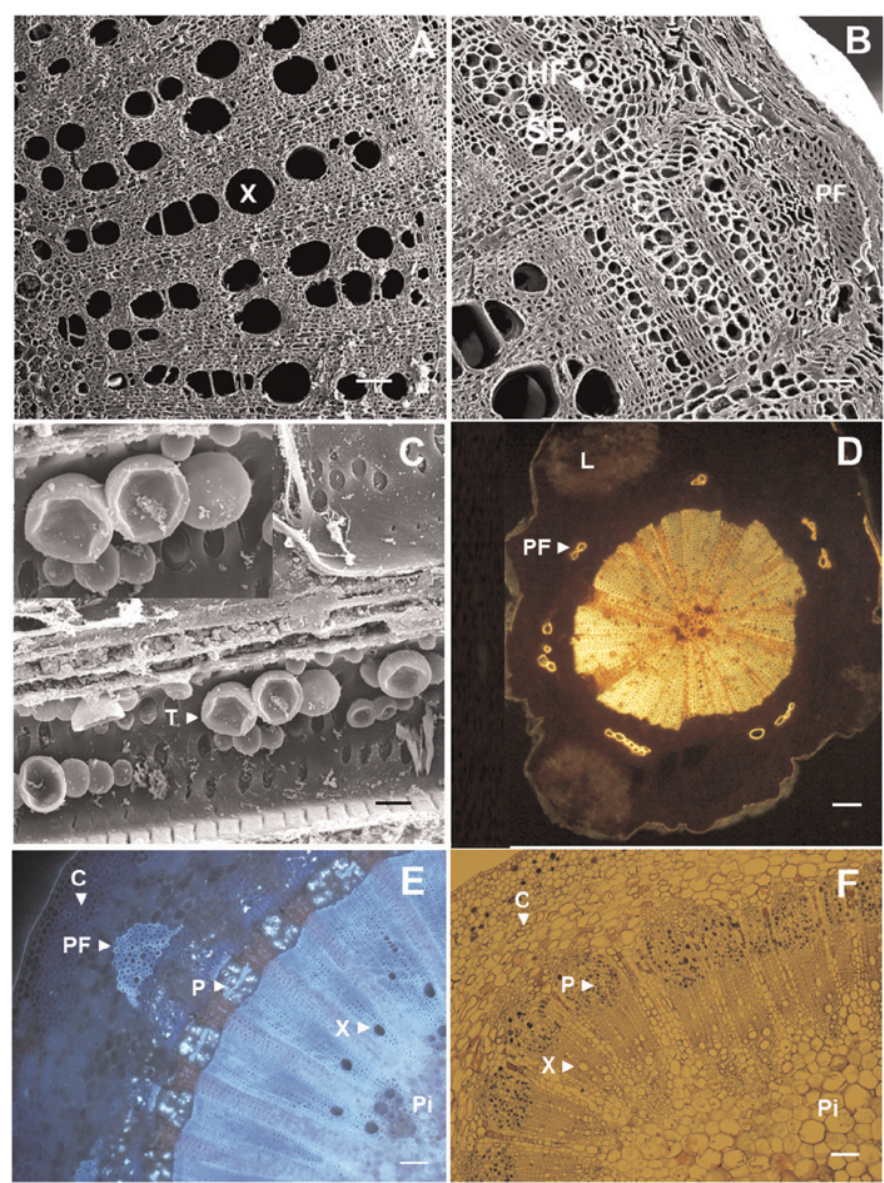

Fig. 6. Scanning electron micrographs of 'Cabernet Sauvignon' grape cane transverse section of (A) healthy cane showing diffuse porous xylem vessels, (B) hard and soft bands of secondary phloem in healthy 'Cabernet Sauvignon' cane, and (C) 'Cabernet Sauvignon' cane that bore berry shrivel clusters showing vessels with tyloses, a light micrograph of transverse section of (D) a pedicel from healthy 'Cabernet Sauvignon' berry showing thickened vascular bundles into pie-shaped sectors separated by rays; light micrographs of a transverse section of $(\mathbf{E})$ a peduncle and $(\mathbf{F})$ rachis from a healthy 'Cabernet Sauvignon' cluster framework showing typical arrangement of cortical and vascular tissues resembling those of a healthy cane. Scale bars: $100 \mu \mathrm{m}(\mathbf{A}, \mathbf{D}-\mathbf{F}), 50 \mu \mathrm{m}(\mathbf{B}), 10 \mu \mathrm{m}(\mathbf{C}) . \mathrm{C}=$ cortex; HF = hard phloem; L = lenticel; $\mathrm{PF}=$ phloem fiber; $\mathrm{Pi}=$ pith; $\mathrm{SF}=$ soft phloem; $\mathrm{X}=$ xylem vessels

solute potential of the berry shrivel berries was mostly associated with their parenchyma cells' inability to accumulate sugars. Because an increase in sugars would increase the osmoticum of the vacuole, especially during ripening maintaining turgor pressure while simultaneously maintaining osmotic gradient between itself and phloem allowing continuous flow of sugars toward the sink (Coombe, 1989), the inability to accumulate sugars is a reflection of poor sink strength; i.e., an ability to attract photoassimilates rather than constrained assimilate supply from leaves (source strength). This inference is based on the premise that berry shrivel initiates at veraison and vines that develop berry shrivel berries remain in a state of healthy physiology fixing carbon for berry export and hence growth to occur (Knoll et al., 2006; Krasnow et al., 2009). Apparently, an increased $\psi_{\mathrm{S}}$ and structurally challenged membrane do not provide a conducive environment for vacuolar swelling, which is one of the predominant phenomena of ripening (Davies and Robinson, 1996). Furthermore, the high
$\psi_{\mathrm{S}}$ was responsible for poor color development (Figs. 4A and 4C) and also flaccidity of berry shrivel berries (Fig. 4G) because sugars have been known to maintain turgor and stimulate anthocyanin in a wide range of angiosperms, including grape (Castellarin et al., 2011; Coombe, 1976; Diakou et al., 1997).

Conversely, the $\psi_{\mathrm{S}}$ of healthy berries compares favorably with published sources previously; e.g., for "Cabernet Sauvignon' grape juice as -3 to $-4 \mathrm{MPa}$ by Considine and Kriedemann (1972). Such decrease in $\psi_{\mathrm{S}}$ of grape juice is mostly brought about by the accumulation of the sugars (glucose and fructose) and cations such as potassium (K), the organic and inorganic osmolytes, respectively, integral to expansive growth and ripening as mentioned previously. Conversely, the $\psi_{\mathrm{S}}$ of berry shrivel berries was rather similar to relatively low sugar-accumulating fruit crops such as apple [Pyrus malus L. (Mills et al., 1997)] or pear [Pyrus pyrifolia (L.) Nijisseiki (Behboudian and Lawes, 1994)]. Although $\mathrm{K}$ is recognized to be the solute largely responsible for lowering the solute potential in root xylem vessels enabling osmotic water absorption by the root (Lauchli, 1984), it is the chief cation accumulated during ripening in grape berries (Mpelasoka et al., 2003) as evident from differences in the accumulation pattern between healthy and berry shrivel. Thus, it is reasonable to posit that some of the alterations in the morphoanatomy of berry shrivel berries arose from their lack of accumulating $\mathrm{K}$ in view of its multiple roles in berry growth and development such as its contributions to charge balance and cell volume, phloem loading, unloading, and translocation of solutes into berry (Mpelasoka et al., 2003) and maintenance of membrane integrity (Peters and Chin, 2007).

In conclusion, as yet, we do not know what precisely causes berry shrivel; however, the findings of the present study derived from an integrated approach about the symptomatology, morphoanatomy, and composition discussed in the context of berry water relations is a major step toward revealing the unknowns of berry shrivel. Ascertaining such features of this phenomenon will lead to essential factual clues to its mechanistic basis allowing formulation of preventive measures to minimize the incidence of berry shrivel. Eventually, this will circumscribe yield losses and improve fruit quality.

\section{Literature Cited}

Behboudian, M.H. and G.S. Lawes. 1994. Fruit quality in 'Nijisseiki' Asian pear under deficit irrigation: Physical attributes, sugar and mineral content, and development of flesh spot decay. N. Z. J. Crop Hort. Sci. 22:393-400.

Bondada, B.R. 2011. Anomalies in structure, growth characteristics, and nutritional composition as induced by 2, 4-D drift phytotoxicity in grapevine leaves and clusters. J. Amer. Soc. Hort. Sci. 136:165176.

Bondada, B.R., M. Keller, and G. Hall. 2009. Compositional and anatomical characterization of SOUR berry. Proc. GiESCO 16th Intl. Symp., Davis, CA. p. 157-159.

Bondada, B.R., M.A. Matthews, and K.A. Shackel. 2005. Functional xylem in the post-veraison grape berry. J. Expt. Bot. 56:2949-2957.

Boyer, J.S. and W.K. Silk. 2004. Hydraulics of plant growth. Funct. Plant Biol. 31:761-773.

Brady, C.J. 1987. Fruit ripening. Annu. Rev. Plant Physiol. 38:155178.

Cadot, Y., M.T. Minana-Castello, and M. Chevalier. 2006. Anatomical, histological, and histochemical changes in grape seeds from Vitis vinifera L. cv Cabernet franc during fruit development. J. Agr. Food Chem. 54:9206-9215. 
Castellarin, S.D., G.A. Gambetta, W. Wada, K.A. Shackel, and M.A. Matthews. 2011. Fruit ripening in Vitis vinifera: Spatiotemporal relationships among turgor, sugar accumulation, and anthocyanin biosynthesis. J. Expt. Bot. 62:4345-4354.

Ceponis, M.J., R.A. Cappellini, J.M. Wells, and G.W. Lightner. 1987. Disorders in plum, peach, and nectarine shipments to the New York market, 1972-1985. Plant Dis. 71:947-952.

Chen, G., R. Hackett, D. Walker, A. Taylor, Z. Lin, and D. Grierson. 2004. Identification of a specific isoform of tomato lipoxygenase (TomloxC) involved in the generation of fatty acid-derived flavor compounds. Plant Physiol. 136:2641-2651.

Considine, J.A. and P. Kriedemann. 1972. Fruit splitting in grapes: Determination of the critical turgor pressure. Aust. J. Agr. Res. 23:17-24.

Coombe, B.G. 1976. The development of fleshy fruits. Annu. Rev. Plant Physiol. 27:207-228.

Coombe, B.G. 1989. Grape berry as a sink. Acta Hort. 239:149-158. Coombe, B.G. 1992. Research on development and ripening of the grape berry. Amer. J. Enol. Viticult. 43:101-110.

Davies, C. and S.P. Robinson. 1996. Sugar accumulation in grape berries. Cloning of two putative vacuolar invertase cDNAs and their expression in grapevine tissues. Plant Physiol. 111:275-283.

DeBolt, S., W.J. Hardie, S.D. Tyerman, and C.M. Ford. 2004. Composition and synthesis of raphide crystals and druse crystals in berries of Vitis vinifera L. cv. Cabernet Sauvignon: Ascorbic acid as precursor for both oxalic and tartaric acids as revealed by radiolabelling studies. Aust. J. Grape Wine Res. 10:134-142.

Diakou, P. and J. Carde. 2001. In situ fixation of grape berries. Protoplasma 218:225-235.

Diakou, P., A. Moing, L. Svanella, N. Ollat, D.B. Rolin, M. Gaudillere, and J.P. Gaudillere. 1997. Biochemical comparisons of two grape varieties differing in juice acidity. Aust. J. Grape Wine Res. 3:1-10.

Ebadi, A., M. Sedglev, P. May, and B.G. Coombe. 1996. Seed development and abortion in Vitis vinifera L. cv. Chardonnay. Intl. J. Plant Sci. 157:703-712.

Frey-Wyssling, A. 1981. Crystallography of the two hydrates of crystalline calcium oxalate in plants. Amer. J. Bot. 68:130-141.

Fuentes, S., W. Sullivan, J. Tilbrook, and S.D. Tyerman. 2010. A novel analysis of grapevine berry tissue demonstrates a variety-dependent correlation between tissue vitality and berry shrivel. Aust. J. Grape Wine Res. 16:327-336.

Gonzalez, M.E., J.A. Jernstedt, D.C. Slaughter, and D.M. Barrett. 2010. Influence of cell integrity on textural properties of raw, high pressure, and thermally processed onions. J. Food Sci. 75:409-416.

Guichard, S., N. Bertin, C. Leonard, and C. Gary. 2001. Tomato fruit quality in relation to water and carbon fluxes. Agronomie 21:385392.

Hall, G., B.R. Bondada, and M. Keller. 2011. Loss of rachis cell viability is associated with ripening disorders in grapes. J. Expt. Bot. 62:1145-1153.

Hardie, W.J., T.P. O’Brien, and V.G. Jaudzems. 1996. Morphology, anatomy and development of the pericarp after anthesis in grape, Vitis vinifera L. Aust. J. Grape Wine Res. 2:97-142.

Keller, M. 2010. Science of grapevines-Anatomy and physiology. Elsevier Academic Press, Burlington, MA.

Keller, M., J.P. Smith, and B.R. Bondada. 2006. Ripening grape berries remain hydraulically connected to the shoot. J. Expt. Bot. 57:2577-2587.

Kliewer, W.M. 1967. Concentration of tartrates, malates, glucose and fructose in the fruits of the genus Vitis. Amer. J. Enol. Viticult. 18:87-96.

Knoll, M., D. Achleitner, and H. Redl. 2006. Response of Zweigelt grapevine to foliar application of potassium fertilizer: Effects on gas exchange, leaf potassium content, and incidence of Traubenwelke. J. Plant Nutr. 29:1805-1817.

Knoll, M., D. Achleitner, and H. Redl. 2010. Sugar accumulation in 'Zweigelt' grapes as affected by 'Traubenwelke'. Vitis 49:101-106.
Koch, K.E. 1996. Carbohydrate modulated gene expression in plants. Annu. Rev. Plant Physiol. Plant Mol. Biol. 47:509-540.

Krasnow, M., M.A. Matthews, and K.A. Shackel. 2008. Evidence for substantial maintenance of membrane integrity and cell viability in normally developing grape (Vitis vinifera L.) berries throughout development. J. Expt. Bot. 59:849-859.

Krasnow, M., N. Weis, R.J. Smith, M.J. Benz, M.A. Matthews, and K.A. Shackel. 2009. Inception, progression, and compositional consequences of a berry shrivel disorder. Amer. J. Enol. Viticult. 60:24-34.

Krasnow, M.N., M.A. Matthews, R.J. Smith, J. Benz, E. Weber, and K.A. Shackel. 2010. Distinctive symptoms differentiate four common types of berry shrivel disorder in grape. Calif. Agr. 64:155-159.

Lauchli, A. 1984. Mechanisms of nutrient fluxes at membranes of the root surface and their regulation in the whole plant, p. 1-25. In: Barber S.A. and D.R. Bouldin (eds.). Roots, nutrient, and water influx, and plant growth. ASA Special Publ. 49. Amer. Soc. Agron., Madison, WI.

Matthews, M.A., G. Cheng, and S.A. Weinbaum. 1987. Changes in water potential and dermal extensibility during grape berry development. J. Amer. Soc. Hort. Sci. 112:314-319.

Matthews, M.A. and K.A. Shackel. 2005. Growth and water transport in fleshy fruit, p. 189-197. In: (edsHolbrook N.M. and M.A. Zwieniecki (eds.). In Vascular transport in plants.), pp. Elsevier Academic Press, Burlington, MA.

Maurel, C., F. Tacnet, J. Guclu, J. Guren, and P. Ripoche. 1997. Purified vesicles of tobacco cell vacuolar and plasma membranes exhibit dramatically different water permeability and water channel activity. Proc. Natl. Acad. Sci. USA 94:7103-7108.

Mills, T.M., M.H. Behboudian, and B.E. Clothier. 1997. The diurnal and seasonal water relations, and composition of 'Braeburn' apple fruit under reduced plant water status. Plant Sci. 126:145-154.

Mpelasoka, B., D.P. Schachtman, and M.T. Treeby. 2003. A review of potassium nutrition in grapevines with special emphasis on berry accumulation. Aust. J. Grape Wine Res. 9:154-168.

Ojeda, H., A. Deloire, A. Carbonneau, A. Ageorges, and C. Romieu. 1999. Berry development of grapevines: Relations between the growth of berries and their DNA content indicate cell multiplication and enlargement. Vitis 38:145-150.

Pennisi, S.V., D.B. McConnell, L.B. Gower, M.E. Kane, and T. Lucansky. 2001. Periplasmic cuticular calcium oxalate crystal deposition in Dracaena sanderiana. New Phytol. 149:209-218.

Peters, J. and C. Chin. 2007. Potassium loss is involved in tobacco cell death induced by palmitoleic acid and ceramide. Arch. Biochem. Biophys. 465:180-186.

Pilati, S., M. Perazzolli, A. Malossini, A. Cestaro, L. Dematte, P. Fontana, A.D. Ri, R. Viola, R. Velasco, and C. Moser. 2007. Genome-wide transcriptional analysis of grapevine berry ripening reveals a set of genes similarly modulated during three seasons and the occurrence of an oxidative burst at veraison. BMC Genomics $8: 428$.

Rančić, D., S.P. Quarrie, and I. Pećinar. 2010. Anatomy of tomato fruit and fruit pedicel during fruit development, p. 851-861. In: MéndezVilas A. and J. Díaz (eds.). Microscopy: Science, technology, applications and education, Vol. 2. Formatex Res. Ctr., Badajoz, Spain.

Rogiers, S.Y., G.N. Mohan Kumar, and N.R. Knowles. 1998. Maturation and ripening of fruit of Amelanchier alnifolia Nutt. are accompanied by increasing oxidative stress. Ann. Bot. (Lond.) 81:203-211.

Ruzin, S.E. 1999. Plant microtechnique and microscopy. Oxford University Press, New York, NY.

Singh, R., R.R. Sharma, and S.K. Tyagi. 2007. Pre-harvest foliar application of calcium and boron influences physiological disorders, fruit yield and quality of strawberry (Fragaria $\times$ ananassa Duch.). Sci. Hort. 112:215-220.

Soltanpour, P.N., G.W. Johnson, S.M. Workman, J.B. Jones, Jr., and R.O. Miller. 1996. Inductively coupled plasma emission spectrometry 
and inductively coupled plasma-mass spectrometry, p. 91-139. In: Sparks D.L. (ed.). Methods of soil analysis. Part 3. Soil Sci. Soc. Amer., Madison, WI.

Sun, Q., T.L. Rost, and M.A. Matthews. 2008. Wound-induced vascular occlusions in Vitis vinifera (Vitaceae): Tyloses in summer and gels in winter. Amer. J. Bot. 95:1498-1505.

Tilbrook, J. and S.D. Tyerman. 2006. Water, sugar and acid: How and where they come and go during berry ripening, p. 4-12. In: Oag D., K. DeGaris S. Partridge C. Dundon M. Francis R. Johnstone and R. Hamilton (eds.). Finishing the job-Optimal ripening of Cabernet Sauvignon and Shiraz. Austral. Soc. Viticult. Oenol., Adelaide, Australia.
Tilbrook, J. and S.D. Tyerman. 2008. Cell death in grape berries: Varietal differences linked to xylem pressure and berry weight loss. Funct. Plant Biol. 35:173-184.

Trippi, V.S., X. Gidrol, and A. Pradet. 1989. Effect of oxidative stress caused by oxygen and hydrogen peroxide on energy metabolism and senescence in oat leaves. Plant Cell Physiol. 30:157-162.

Watkins, C.B. 2007. The effect of 1-MCP on the development of physiological storage disorders in horticultural crops. Stewart Postharvest Rev. 2:1-6.

Zhang, B., K. Chen, J. Bowen, A. Allan, R. Espley, and S. Karunairetnam. 2006. Differential expression within the LOX gene family in ripening kiwifruit. J. Expt. Bot. 57:3825-3836. 